Archives de sciences sociales des religions

114 | avril-juin 2001

Varia

\title{
FRIJHOFF (Willem), Heiligen, idolen, iconen
}

Nimègue, Éditions SUN, 1998, 96 p.

André Tihon

\section{CpenEdition}

Journals

Édition électronique

URL : https://journals.openedition.org/assr/20891

DOI : 10.4000/assr.20891

ISSN : $1777-5825$

Éditeur

Éditions de l'EHESS

Édition imprimée

Date de publication : 1 juin 2001

Pagination : 138

ISBN : 2-222-96704-X

ISSN : 0335-5985

Référence électronique

André Tihon, «FRIJHOFF (Willem), Heiligen, idolen, iconen », Archives de sciences sociales des religions

[En ligne], 114 | avril-juin 2001, document 114.77, mis en ligne le 19 août 2009, consulté le 21

septembre 2021. URL : http://journals.openedition.org/assr/20891 ; DOI : https://doi.org/10.4000/ assr.20891

Ce document a été généré automatiquement le 21 septembre 2021

(c) Archives de sciences sociales des religions 


\section{FRIJHOFF (Willem), Heiligen, idolen, iconen}

Nimègue, Éditions SUN, 1998, 96 p.

André Tihon

\section{RÉFÉRENCE}

FRIJHOFF (Willem), Heiligen, idolen, iconen, Nimègue, Éditions SUN, 1998, 96 p.

1 Ce texte sur "Saints, idoles, icônes » est la version amplifiée, et abondamment fournie de notes, de la leçon inaugurale de l'auteur comme professeur d'histoire des Temps modernes à l'Université libre d'Amsterdam. Cette nomination d'un historien du monde catholique dans une université créée par la tendance conservatrice de l'Église réformée des Pays-Bas est déjà un événement. L'A. est un ancien élève et collaborateur d'Alphonse Dupront au Centre d'anthropologie religieuse européenne de l'École des Hautes Études en Sciences Sociales. On retrouvera dans cet exposé l'ampleur de la problématique et des angles d'approche mais aussi l'expression parfois elliptique de la pensée de son maître. Après un aperçu de la recherche sur la sainteté depuis l'ouvrage de Pierre Delooz, Sociologie et canonisation (Liège-La Haye, 1969), l'A. nous entraîne dans un vaste panorama d'une approche qui dépasse la sphère catholique traditionnelle pour déboucher sur les autres confessions chrétiennes mais aussi sur les modèles dans nos sociétés sécularisées. Constatant le retour en force des saints comme des grands hommes dans la société comme parmi les historiens, son propos est d'étudier non les saints mais les manières dont leur évocation fonctionne pour les individus et les sociétés dans une perspective de sociologie de la culture plutôt que des religions. Il est impossible de donner dans un bref compte rendu toute la richesse d'un exposé aussi programmatique qui parfois déplace et subvertit les acceptions communes des trois termes repris. Dans la ligne de Rudolf Otto, il étudie les saints comme des personnes douées par Dieu de dons spéciaux, en relations privilégiées avec le divin et participant ainsi au sacré. Dans la tradition catholique, leur vie extraordinaire en fera plutôt des 
intercesseurs que des exemples même si cette dernière caractéristique reste présente. La comparaison par l'A. du saint avec l'idole, personne ou chose comme image de la divinité avec le numineux qui la caractérise, a suscité beaucoup de réactions. Pourtant sur la couverture de l'ouvrage, le spot publicitaire utilisant la photo du footballeur brésilien Ronaldo, debout, les bras en croix, dominant, comme la statue monumentale du Sacré-Cœur, la baie de Rio de Janeiro, est un exemple frappant d'une nouvelle divinité tutélaire mais également, pour les jeunes des milieux populaires, un symbole d'une libération possible de la misère. La définition de l'icône, reprise à C. S. Peirce, comme "signe qui renvoie à ce qu'il représente ", s'écarte davantage de la perception courante que nous en avons. Pour l'A., l'icône, qu'elle soit événement ou personne, est symbole d'une valeur ou d'une attitude qui se réfère à une personne historique indépendamment de ses qualités concrètes. L'icône peut être plurielle : les portraits d'Érasme à Rotterdam sont exemplaires d'une telle diversité au cours des siècles. Icône de l'érudit, elle devient celle de l'hérétique pour les soldats de Philippe II, de la tolérance pour les arminiens du XVII siècle, et de l'engagement critique après la Seconde Guerre mondiale. De multiples exemples font la richesse suggestive de ce discours inaugural. Ils montrent également les transferts d'une catégorie à l'autre, du saint à l'idole ou à l'icône et inversement, et les registres divers, religieux, politiques ou culturels, où ces phénomènes se manifestent. On souhaiterait qu'une telle esquisse soit publiée dans une langue accessible à un plus grand nombre de chercheurs. 